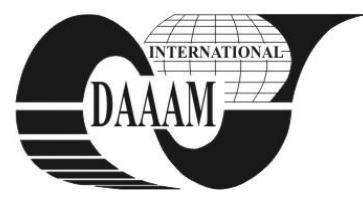

Annals of DAAAM for 2011 \& Proceedings of the 22nd International DAAAM Symposium, Volume 22, No. 1, ISSN 1726-9679 ISBN 978-3-901509-83-4, Editor B. Katalinic, Published by DAAAM International, Vienna, Austria, EU, 2011 Make Harmony between Technology and Nature, and Your Mind will Fly Free as a Bird Annals \& Proceedings of DAAAM International 2011

\title{
SOLDERING HIGH-PURITY MATERIALS WITH CU SUBSTRATE
}

\author{
KOLENAK, R[oman] \& CHACHULA, M[ichal]
}

\begin{abstract}
The work deals with joining targets for PVD sputtering. The task was oriented to suggestion of a technology suitable for joining a wide scope of high-purity materials with copper substrate. A solderable coating formed of three $\mathrm{Cr} / \mathrm{Ni} / \mathrm{Ag}$ layers was deposited on high-purity material. The silver layer is dissolved in solder during soldering at formation of intermetallic phases $\left(\mathrm{AgIn}_{2}\right.$ and $\left.\mathrm{Ag}_{3} \mathrm{Sn}\right)$, assuring a good surface wetting in a short time. The shear strength of joints for different In-based solders was determined. The highest strength was achieved with In48Sn solder, with the lowest melting point, what seems to be advantageous from the viewpoint of soldering process
\end{abstract}

Key words: $P V D$ target, soldering, solderable coating, $\mathrm{Al}_{2} \mathrm{O}_{3}$ ceramics, shear strength

\section{INTRODUCTION}

Thin solderable coatings are desirable mainly in electronics and micro-electronics, since soldering of parts should be executed in very short times. The coatings on substrate may be either meltable or dissolvable. Dissolvable coating may be composed of one metal or of a system of metallic layers. Disadvantage of a monolithic dissolvable coating consists in its high price and greater possibility of solder de-wetting caused by dissolving (erosion) of the coating. The dissolvable solderable coating for electronics mostly consists of an adhesive layer $(\mathrm{Cr}, \mathrm{Ni}, \mathrm{Ti}, \mathrm{Al})$ diffusion barrier $(\mathrm{Ni}, \mathrm{Cr}, \mathrm{Pt} \mathrm{Pd})$ and a solderable layer $(\mathrm{Ag}, \mathrm{Au}, \mathrm{Cu}, \mathrm{Ni})$. Its composition depends on substrate material, soldering parameters and conditions (Schmidtova et al., 2011).

For higher soldering temperatures and the lead-free solders, dissolvable coatings must be selected. It is necessary to use a backing coating based on $\mathrm{Ni}, \mathrm{Pd}$, Pt under the solderable layer, since this exerts low solubility during the soldering process, but on contrary is also exerts poorer solderability at short time. Advantageous may be also to use a combined coating composed of more and less dissolvable metals, for example NiPdAu, PtAg (Clauberg et al., 2011).

The de-wetting effect seems to be an important factor in soldering materials with thin dissolvable coatings. This occurs mainly in the case when diffusion barrier is not used. The price of precious metals presses to use the thinnest possible coatings that still meet the requirements for a good solderability. Owing to above mentioned, it is important to prevent the de-wetting caused by improper soldering procedure. The research was aimed at solving the issue of soldering the high-purity materials (with the purity grade higher than $4 \mathrm{~N}$ ) with a copper substrate (Fig. 1). The high-purity materials are used as the de-sputtering targets for PVD sputtering. A wide scope of metallic (Al, Mg, $\mathrm{Ti}, \mathrm{V}, \mathrm{Cr}, \mathrm{Mn}, \mathrm{Mo}, \mathrm{Ni}, \mathrm{Cu}, \mathrm{Zr}, \mathrm{Hf}$, Ta, W etc.), non-metallic ( $\mathrm{Si}, \mathrm{Ge}, \mathrm{C}$ etc.) and ceramic $\left(\mathrm{Al}_{2} \mathrm{O}_{3}, \mathrm{SiO}_{2}, \mathrm{ITO}, \mathrm{TiO}_{2}, \mathrm{SiC}\right.$ etc. $)$ materials, with important position in electronics and microelectronics is used for the targets (Medvedovski et al., 2008).

The main requirement was to develop the technology that would be as versatile as possible for a wide scope of materials. Due these reasons, the technology of soldering with application of thin solderable coatings was employed.

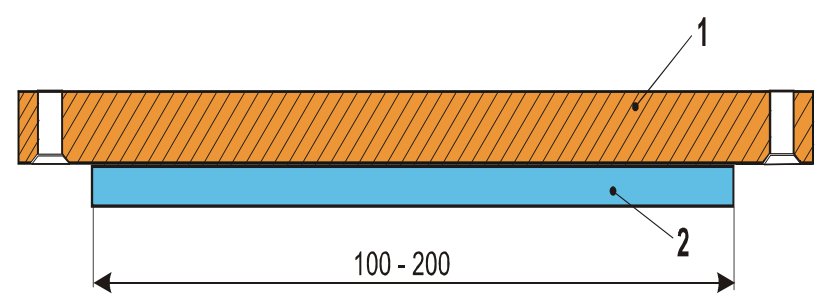

Fig. 1. Schematic representation of a joint at joining the targets of high-purity materials destined for PVD sputtering - (1) copper cooling plate, (2) high-purity target material

\section{EXPERIMENTAL}

A combined dissolvable coating, composed of more and less dissolvable metals was suggested for experiments. The coating consisted of a system of $\mathrm{Cr} / \mathrm{Ni} / \mathrm{Ag}$ layers, where the tin layer exerted adhesive function, the nickel layer forms a diffusion barrier and the nickel layer assures a good solderability and spreadability in a short time (Fig. 2). The technology of PVD sputtering was used for coating preparation.

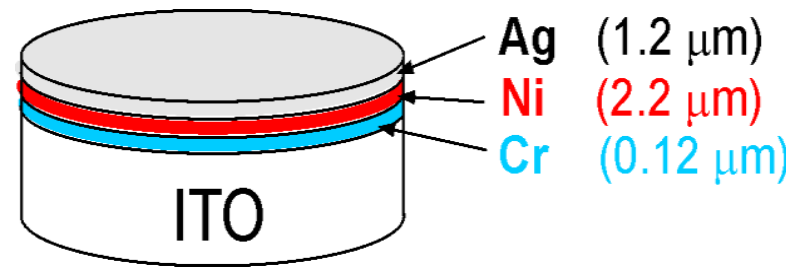

Fig. 2. Distribution of metallic layers on a ceramic substrate

The coating system was prepared on the ceramic materials $\mathrm{Al}_{2} \mathrm{O}_{3}$, ITO (Indium-Tin Oxide) and Si. All were of 4N5 purity grade. Copper with $3 \mathrm{~N} 5$ purity grade was used as the metallic substrate. The temperature interval in which soldering must be performed to prevent the de-wetting of silver layer was determined on the basis of binary diagram (Fig. 3) and with respect to thickness of $\mathrm{Ag}$ layer and its solubility rate.

Based on this finding, the following solders were suggested: pure In (melting point $157{ }^{\circ} \mathrm{C}$ ), In30Sn (melting point $135^{\circ} \mathrm{C}$ ) and $\operatorname{In} 48 \mathrm{Sn}$ (melting point $118^{\circ} \mathrm{C}$ ). The soldering temperature was selected to be by $20^{\circ} \mathrm{C}$ higher than the melting point, with a minimum hold-up time necessary for a good solder spreading (Plötner at al., 2003).

Heating of specimens was assured by the hot plate method with temperature control by use of $\mathrm{NiCr} / \mathrm{NiSi}$ thermocouple.

\section{RESULTS}

The shear strength of joints fabricated of high-purity $\mathrm{Al}_{2} \mathrm{O}_{3}$, ITO and $\mathrm{Si}$ materials by use of combined coating was determined. The joint fracture occurred preferably in solder. Shear strength of joints was higher than the tensile strength of solder proper. The highest shear strength was achieved with In48Sn solder, whereas the lowest was attained with In-based solder. The found results are shown in Fig. 3. 


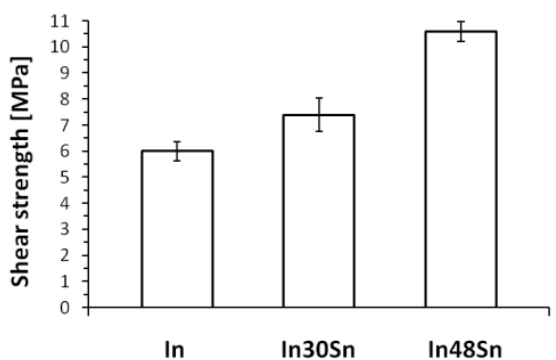

Fig. 3 Shear strength in dependence on solder composition

The EDX analysis has revealed the presence of $\operatorname{AgIn}_{2}$ and $\mathrm{Ag}_{3} \mathrm{Sn}$ phases in the vicinity of $\mathrm{Ag}$ coating/solder boundary. Formation of these phases was confirmed also by equilibrium binary diagrams (Fig. 4). The new formed phases form fine dispersion inclusions in the matrix. The amount of Ag bound in the intermetallic phases decreases in the direction from boundary to solder.
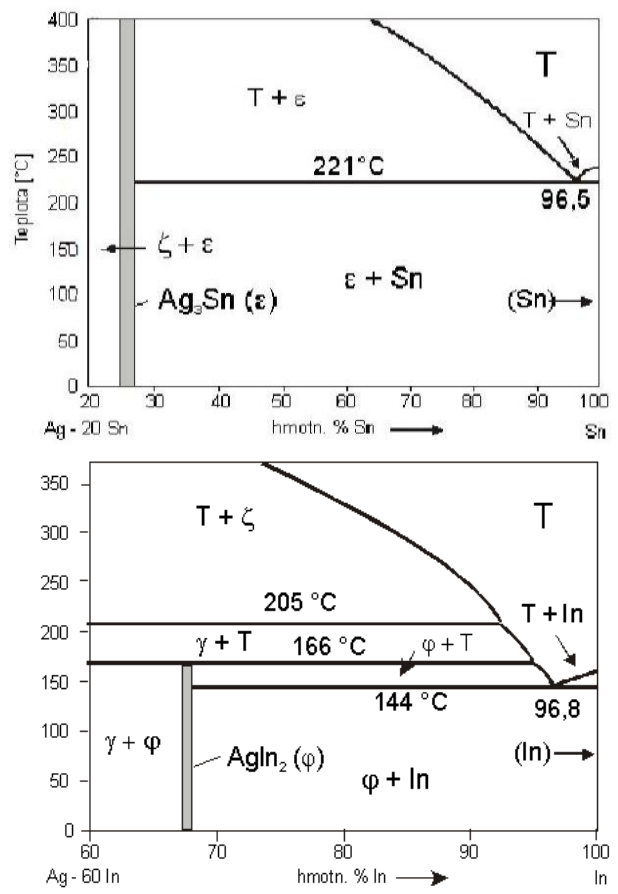

Fig. 4. Selected part of $\mathrm{Ag}$ - Sn and Ag - In binary diagrams (Humpston et al., 1994)

An example of microstructure in soldered joint consisted of silicon with $\mathrm{Cr} / \mathrm{Ni} / \mathrm{Ag}$ layers - In $48 \mathrm{Sn}$ solder - $\mathrm{Cu}$ is shown in Fig. 5. Soldering was performed at temperature $135{ }^{\circ} \mathrm{C}$ in the air with minimum hold-up time at soldering temperature. A sound bond of solder with a silver layer from silicon side can be observed in Fig. 5. The silver layer is partially dissolved in solder and thus it assures a good wetting of silicon surface with metallic coating. Following from the In-Sn binary diagram, the solder matrix is of eutectic composition.

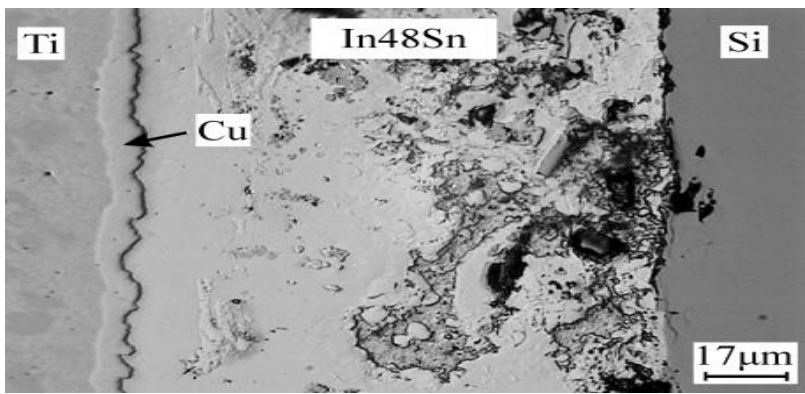

Fig. 5 Boundary of $\mathrm{Si}(\mathrm{Cr} / \mathrm{Ni} / \mathrm{Ag})-\mathrm{In} 48 \mathrm{Sn}$ solder - $\mathrm{Cu}(\mathrm{Ti})$ joint
Fig. 6 shows a target of high-purity $\mathrm{Al}_{2} \mathrm{O}_{3}$ ceramics for PVD process after partial sputtering. The target was soldered by application of $\mathrm{Cr} / \mathrm{Ni} / \mathrm{Ag}$ system of layers and really tested in practice.

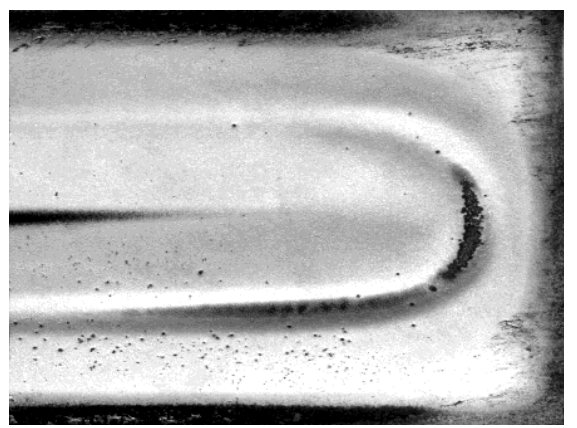

Fig. 6. A part of target for PVD process after sputtering

\section{CONCLUSIONS}

A procedure for solving the solderability of thin coatings by use of lead-free solders was developed and experimentally approved.

A system of solderable $\mathrm{Cr} / \mathrm{Ni} / \mathrm{Ag}$ layers formed by $\mathrm{PVD}$ sputtering on substrates of $\mathrm{Al}_{2} \mathrm{O}_{3}$, ITO and $\mathrm{Si}$ high-purity materials was approved experimentally.

The silver layer from combined coating is partially dissolved in solder and thus it assures a good wetting of metallic coating on the non-metallic or ceramic material. Fine inclusions of intermetallic $\mathrm{AgIn}_{2}$ and $\mathrm{Ag}_{3} \mathrm{Sn}$ phases are formed in solder matrix in the vicinity of boundary.

The joint fracture occurred preferably in solder. The highest shear strength was achieved with In48Sn solder, whereas the lowest was attained with In-based solder.

The developed technology of joining high-purity materials for PVD targets is versatile and applicable for a wide scope of metallic and non-metallic materials. All tested solders are principally applicable also for soldering in the air. Regarding the joint strength, melting point and economy merits, the most suitable seems to be the In $48 \mathrm{Sn}$ solder of close-to-eutectic composition.

\section{ACKNOWLEDGEMENTS}

This contribution was prepared with the support of VEGA 1/0211/11 project - Development of lead-free solder for higher application temperatures and research of material solderability of metallic and ceramic materials.

\section{REFERENCES}

Schmidtova, T., Soucek, P., Vasina, P., \& Schafer, J. (2011). Study of hybrid PVD - PECVD process of Ti sputtering in argon and acetylene. Surface and Coatings Technology, Vol. 205., No. 2, (299-302), ISSN 0257-8972

Clauberg, H., Backus, P. \& Chylak, B. (2010). NickelPalladium bond pads for copper wire bonding. Microelectronic Reliability, Vol. 51., No. 1, (75-80), ISSN 0026-2714

Medvedovski, E., Alvarez, N., Yankov, O. \& Olsson, M. K. (2008). Advanced indium-tin oxide ceramics for sputtering targets. Ceramics International, Vol. 34., No. 5, (11731182), ISSN 0272-8842

Plötner, M., Donat, B. \& Benke A. (2003) Deformation properties of indium-based solders at 294 and $77 \mathrm{~K}$. Cryogenics, Vol. 31., No. 3, (159-162), ISSN 0011-2275

Humpston, G., Jacobson, M. D. (1994) Principles of Soldering and Brazing, ASM International, Vol. 12., No 2, (281-282), ISBN 0-87170-462-5 